assuming that the popular clinical subdivisions into endogenous and other specified varieties correspond to biologically homogeneous groupings. Certainly it has not been possible to relate to a particular clinical form of the disease the slight changes observed in water and sodium metabolism of patients who are recovering under treatment. Nor can this be done for the high morning levels of cortisol in the plasma of depressed patients-a finding which corresponds to the increase in plasma-level of cortisol that occurs in normal persons subjected to environmental stress (such as an impending surgical operation, final examinations, rowing in a university boat race) or to experimental situations which induced anxiety and distress. ${ }^{3}$ Among depressed patients, ${ }^{3}$ those with retarded depression were found to have higher mean levels of cortisol than those who were agitated and weeping. Clinical improvement was associated with a fall in the plasma corticosteroid level, except in some chronically ill patients in whom with clinical improvement there was a rise in plasma corticosteroids. As usual in such studies the situation is complex and the physiological change seems not to be specifically related to the clinical symptoms.

The catecholamine hypothesis, to which Professor Miller referred, is stimulating but unconfirmed. When it was discovered that monoamine oxidase inhibitors could bring about recovery from a depressive illness, inquiry into the part played by cerebral monoamines in melancholia was quickened, and many studies have now suggested that these drugs act on a disorder of brain-amine metabolism. Depression, it is postulated, is associated with a deficiency of cerebral amines. Besides studies in man of the amount of noradrenaline and dopamine excreted in the urine during depression, direct measurement of catecholamines in the brain of animals has supplied some contingent evidence about their relation to emotion. Mice, rats, and guinea-pigs were subjected to stress by exposing them to fight with aggressive animals of the same species, giving them repeated electric shocks, immobilizing them, or stimulating the brain through implanted electrodes. ${ }^{4}$ In these animals a 10 to $30 \%$ decrement was found in the amount of noradrenaline in the brain. It was concluded that prolonged severe emotional upset activated a large number of cerebral neurones, which released noradrenaline; the concentration of serotonin and dopamine in the brain, however, did not alter. Unfortunately measurement of the amount of noradrenaline excreted in the urine has given discrepant results. This test is in any case potentially deceptive, since it is probable that only a small proportion of the noradrenaline liberated in the brain passes the bloodbrain barrier, the bulk of the noradrenaline in blood and urine deriving from the peripheral sympathetic nervous system.

The biochemical explanation designed to reconcile the antidepressant action of imipramine with the catecholamine hypothesis has been the occasion of further investigation of the metabolites of noradrenaline, particularly normetadrenaline and vanillylmandelic acid. J. J. Schildkraut and his colleagues at Bethesda have shown that as depressed patients improve while under treatment with imipramine there is a gradual increase in the amount of normetadrenaline excreted. They think it probable that this can be taken as an indication

1 Miller, H., Brit. med. 7., 1967, 1, 257.

Michael, R. P., and Gibbons, J. L., Int. Rev. Neurobiol., 1963, 5, 243.

- Bliss, E. L., and Zwanziger, J., f. psychiat. Res., 1966, 4, 189.

- Schildkraut, J. J., Green, R., Gordon, E. K., and Durell, J., Amer. f. Psychiat., 1966, 123, 690. of the amount of noradrenaline activity in the nervous system. ${ }^{\mathrm{s}}$

Incomplete and uncertain though our present information on these matters is, it warrants Professor Miller's judicious conclusion that the catecholamine hypothesis "furnishes a convenient frame of reference for both reflection and investigation in this important and absorbing field of medicine."

\section{Prognosis in Breast Cancer}

One way of estimating the prognosis of patients with breast cancer is to measure the corticosteroids excreted in the urine. ${ }^{1}$ In particular the urinary levels of aetiocholanolone (an androgen metabolite) and the 17-hydroxycorticosteroids have been measured and the measurements combined to make a "discriminant function" which was found to be helpful in forecasting response to treatment and prognosis.

The preoperative levels of these corticosteroids gave a reasonably accurate prediction of the response of a patient with advanced breast cancer to adrenalectomy or hypophysectomy. Further, when measured in patients who had undergone mastectomy for breast cancer the urinary corticosteroids gave a good indication of the chances of recurrence. ${ }^{2}$

Many of these findings have since been independently confirmed, ${ }^{3}$ but the procedures for measuring the steroids are so complex that they can be carried out only in specialized laboratories, and hence are of little direct clinical value. Recently H. Miller, J. A. Durant, A. G. Jacobs, and Jacqueline $\mathrm{F}$. Allison ${ }^{5}$ have reported an alternative method of using urinary corticosteroid measurements for predicting the response to the treatment of breast cancer. While employing the same concept of measuring androgens and corticoid metabolites, they have found that a discriminant based on a simple ratio of the pooled 11-deoxy-17-oxosteroids (these include aetiocholanolone but also other androgen metabolites) and the 17-hydroxycorticosteroids can be compared almost exactly with the original discriminant in which aetiocholanolone had to be measured specifically.

The original and the new discriminants were measured in 94 women with breast cancer and 55 healthy women. A remarkable correlation was noted both in the prediction of response of patients with advanced breast cancer to endocrine ablation and also in the variation of the discriminant value with age in normal women. The great advantage of this new approach is that the measurement of the total 11-deoxy-17oxosteroids is well within the compass of most hospital laboratories. The information, when available to those surgeons who perform adrenalectomy or hypophysectomy, can be used to predict the response of their patients.

It has also been hinted that the original discriminant might be a valuable tool to detect a group of women in the normal population who stand a high risk of developing breast cancer. ${ }^{\circ}$ This group could then be examined frequently, both clinically and by mammography. If a carcinoma developed it

\footnotetext{
Brit. med. F., 1965, 2, 1198.

Bulbrook, R. D., Hayward, J. L., and Thomas, B. S., Lancet, 1964, 1, 945 .

- Juret, P., Hayem, M., and Fleisler, A., 7. Chir. (Paris), 1964, 87, 409.

- Kumaoka, S., Abe, Ö., Sakauchi, N., Takatani, O., and Kusama, M. Abstr. Ninth Int. Cancer Congress, 1966, p. 653.

Miller, H., Durant, J. A., Jacobs, A. G., and Allison, J. F., Brit. med. f., 1967, 1, 147 .

Hayward, J. L., Proc. roy. Soc. Med., 1966, 59, 1204.

Philip, J. F., Brit. med. F., 1967, 1, 323.
} 
would be detected at a very, early stage and the appropriate treatment could be instituted. In general, the earlier the diagnosis the more effectual the treatment. ${ }^{7}$ The approach seems at the moment to stand a better chance of improving recurrence and survival rates than is likely to be accomplished by any foreseeable changes in treatment. If used on a national scale, with the original methods, this scheme of early detection would require vast resources. The new simplification may overcome this difficulty and make a development of this nature more probable.

\section{Imported Tropical Disease}

"When and where were you last abroad ?" is increasingly a question that a doctor must ask his patient. International travel is becoming commonplace, whether on business or holiday, and immigrants also swell the numbers coming to Great Britain from overseas. As a result tropical disease is something for which doctors here must constantly be on the look-out if it is to be detected and tragedies averted. The list of such tragedies is formidable, and letters in this issue of the B.M.7. (page 496) draw attention to the matter again.

Malaria heads the list of tropical diseases to be suspected as a cause of the patient's symptoms. There can be no disease which passes so readily as Plasmodium falciparum infection from a condition easy to treat into one that may be hopeless. The point is exemplified by the series of such patients with severe renal failure reported by $R$. C. Jackson and A. W. Woodruff. ${ }^{1}$ It is believed that one or two patients die every year in Britain of malaria which had been unsuspected, and several others have severe illnesses which could be prevented.

Trypanosomiasis is being increasingly encountered here and is seldom diagnosed till late in its course. ${ }^{2}$ A recent report $^{3}$ described a patient who had been in hospital for four months before the disease was suspected, the illness being meantime thought to be tuberculous meningitis. The diverse manifestations of leprosy provide a further source of diffculty, aggravated by the tendency of some patients with the disease to conceal it. Amoebic and bacillary dysentery are both commonly contracted by travellers, and amoebic abscess of the liver is a frequently overlooked cause of fever and abdominal discomfort. Schistosomiasis with its insidious onset and long latent period is often a cause of obscure genitourinary and alimentary symptoms. Smallpox, and even cholera, must be kept in mind as possibilities in some cases.

Thus it is most important to bear tropical disease in mind and to ask all patients, as an essential part of history-taking, where and when they were last abroad. B. G. Maegraith has recently given a useful synopsis in a pamphlet distributed by Ciba Ltd. ${ }^{4}$ of tropical diseases likely to be imported into Britain. The series of articles appearing at monthly intervals in the B.M.F. may also be of help, even though they are intended primarily for our many readers in tropical countries. A textbook on the subject, such as those admirable volumes by Adams and Maegraith ${ }^{5}$ and by Hargreaves and Morrison, ${ }^{6}$ finds a useful place on the shelf. But the most important thing is to think of tropical diseases and refer to a specialized

1 Jackson, R. C., and Woodruff, A. W., Brit. med. f., 1962, 1, 1367. Willett, K. C., ibid., 1965, 2, 167.

' F. trop. Med. Hyg., 1965, 68, 296.

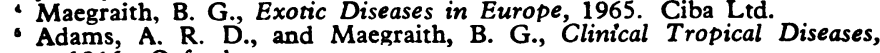
1966. Oxford.

- Hargreaves, W. H., and Morrison, R. J. G., The Practice of Tropical Medicine, 1965. London. centre patients possibly suffering from them. Of these special centres there are three in Britain-the Hospital for Tropical Diseases, London; the Liverpool School of Tropical Medicine ; and the Tropical Disease Unit at the City Hospital, Edinburgh.

\section{Bronchial Neoplasms and Hormonal Secretions}

Neoplasms of the lung may secrete hormone-like substances.' Patients with lung tumours may show some of the features of adrenal cortical excess, but the florid clinical picture does not develop, probably because these patients do not survive long enough. C. K. Meador and colleagues ${ }^{2}$ have shown that tumour cells from these patients contain a material identical with or very like adrenocorticotropic hormone, and the cells may in fact secrete this material. Water retention may occasionally be associated with bronchial carcinoma. J. Lee and colleagues ${ }^{3}$ and B. F. Bower and colleagues ${ }^{4}$ suggested that the water retention is due to the secretion of an antidiuretic material by the tumour cells. Subsequently, Lee and his co-workers ${ }^{5}$ extended their investigation and concluded that the antidiuretic material, if not antidiuretic hormone, must be a closely related substance. The evidence is less certain that hypercalcaemia may be due to the secretion of a substance resembling parathyroid hormone by the tumour. ${ }^{6}$ The carcinoid syndrome has been described in association with bronchial neoplasms. ${ }^{7}$

True gynaecomastia in males with lung tumours is well recognized, and removal of the tumour leads to a reduction in size of the breasts. ${ }^{8}$ Recently F. D. Fusco and S. W. Rosen $^{9}$ found that lung tumour tissue removed from patients with gynaecomastia contained large quantities of gonadotropins. These authors considered that the large quantities of gonadotropins released by the tumour cells stimulated the testes to secrete the excess oestrogens which induce the development of the gynaecomastia. Chorionic gonadotropins can induce secretion of oestrogen by the human testes, ${ }^{10}$ but the assay preparation used by Fusco and Rosen would respond to any of the gonadotropins. Their conclusion does not take account of the finding that high levels of oestrogen and gynaecomastia can occur separately. ${ }^{11}$ As well as lung tumours, neoplasms in other situations are also known to produce hormone-like substances.

Thus a new but rare syndrome has appeared. The rare has always excited the clinician, though an awareness of a new condition may show it to be less unusual than originally supposed. It has already been possible to anticipate the presence of a lung tumour on the evidence of hormonal disturbance. Moreover, the finding that neoplasms may secrete hormone-like substances provides a new avenue of approach in cancer research.

See Brit. med. 7., 1965, 1, 4.

Meador, C. K, Liddle, G. W., Island, D. P., Nicholson, W. E., Lucas, C. P., Nuckton, J. G., and Luetscher, J. A., Ұ. clin. Endocr., 1962, 22, 693.

see, J., Jones, J. J., and Barraclough, M. A., Lancet, 1964, 2, 792. 1964, 271, 934.

- Barraclough, M. A., Jones, J. J., and Lee, J., Clin. Sci., 1966, 31, 135.

- Tashiian, A. H., jun., Levine, L., and Munson, P. L., Endocrinology, 1964, 74. 244.

'Hobbs, C. B., and Miller, A. L., f. clin. Parh., 1966, 19, 119

- Greenberg, E., Divertie, M. B., and Woolner, L. B., Amer. F. Med., $1964,36,106$.

- Fusco, F. D., and Rosen, S. W., New Engl. F. Med., 1966, 275, 507.

11 Maddock, W. O., and Nelson, W. O., f. clin. Endocr., 1952, 12, 985.

1 Ginsburg, J., and Brown, J. B., Lancet, 1961, 2, 1274. 